\title{
Species from different taxonomic groups show similar invasion traits
}

\author{
Tina Heger \\ Technische Universität München, Department of Ecology and Ecosystem Management, Restoration Ecology, \\ Emil-Ramann-Str.6, 85350 Freising, Germany, t.heger@wzw.tum.de
}

\section{Sylvia Haider}

Martin Luther University Halle Wittenberg, Institute of Biology/Geobotany and Botanical Garden, Am Kirchtor 1, 06108 Halle (Saale), Germany

\section{Wolf-Christian Saul}

Technische Universität München, Department of Ecology and Ecosystem Management, Restoration Ecology, Emil-Ramann-Str. 6, 85350 Freising, Germany and Leibniz-Institute of Freshwater Ecology and Inland Fisheries (IGB), Müggelseedamm 310, 12587 Berlin, Germany and Freie Universität Berlin, Department of Biology, Chemistry, Pharmacy, Institute of Biology, Königin-Luise-Str. 1-3, 14195 Berlin, Germany

\section{Jonathan M. Jeschke}

Technische Universität München, Department of Ecology and Ecosystem Management, Restoration Ecology, Emil-Ramann-Str. 6, 85350 Freising, Germany and Leibniz-Institute of Freshwater Ecology and Inland Fisheries (IGB), Müggelseedamm 310, 12587 Berlin, Germany and Freie Universität Berlin, Department of Biology, Chemistry, Pharmacy, Institute of Biology, Königin-Luise-Str. 1-3, 14195 Berlin, Germany

\begin{abstract}
Invasion ecology tends to treat taxonomic groups separately. However, given that all invasive species go through the same stages of the invasion process (transport, escape, establishment, spread), it is likely that-across taxa-comparable traits help to successfully complete this process ("invasion traits"). Perhaps not all invasive species have the same invasion traits, but different combinations of invasion traits can be found among invaders, corresponding to different possibilities to become a successful invader. These combinations of invasion traits might be linked to taxonomic affiliation, but this is not necessarily the case. We created a global dataset with 201 invasive species from seven major taxonomic groups (animals, green plants, fungi, heterokonts, bacteria, red algae, alveolates) and 13 invasion traits that are applicable across all taxa. The dataset was analysed with cluster analysis to search for similarities in combinations of invasion traits. Three of the five clusters, comprising $60 \%$ of all species, contain several major taxonomic groups. While some invasion trait frequencies were
\end{abstract}

\section{Discovery}

In 201 species belonging to seven major taxonomic groups (including plants, animals, fungi, bacteria), we searched for cross-taxonomic clusters of similar invasive species. The results revealed that species from different taxonomic groups show similar invasion traits. The patterns in trait combinations reflected a tendency of species to either have traits favourable for one specific stage of the invasion process, or to be specifically promoted by humans. This analysis suggests that there are no universal invasion traits shared by all invasive species, but that invasive species are successful for a number of different reasons represented by different trait combinations ("invader types").

significantly related to taxonomic affiliation, the results show that invasive species from different taxonomic groups often share similar combinations of invasion traits. A post-hoc analysis suggests that 
combinations of traits characterizing successful invaders can be associated with invasion stages across taxa. Our findings suggest that there are no universal invasion traits which could explain the invasion success of all invaders, but that invaders are successful for different reasons which are represented by different combinations of invasion traits across taxonomic groups.

Keywords: alien species, cluster analysis, taxonomic bias, cross-taxonomic study, invasion mechanisms.

\section{Introduction}

Invasion ecology, as many other biological disciplines, is split into taxonomically delineated subdisciplines among which there is limited transfer of knowledge. Some important hypotheses, e.g. enemy release or biotic resistance, are mainly investigated for plants but rarely for animals (1). Vice versa, the hypothesis that islands are more susceptible to invaders than continents has been mainly studied for vertebrates (1). A commonly presented argument in favour of this taxonomic split is that different invasion mechanisms might be relevant for different taxonomic groups (e.g. 2).

Although taxonomic differences certainly are important, there is a challenge to this argument: species of all taxonomic groups have to overcome the same difficulties during the invasion process-they have to be transported to an exotic range where they have to be released or escape; they have to establish a self-sustaining population in the wild; and finally, they have to overcome difficulties with spread (3-7). It is therefore conceivable that invasive species share traits that help overcome such difficulties in transport, escape, establishment and spread, independently of taxonomic group to which they belong.

Cross-taxonomic studies in invasion ecology are rare; however, some studies provided evidence that invasion mechanisms across different taxa are similar. In particular, Pyšek et al. (8) found that, concerning habitat affinity, alien insects are more similar to alien plants than to alien vertebrates. Newsome and Noble (9) analysed traits distinguishing bird and plant invaders in Australia. They found analogies between invasive bird and plant species, particularly in regards to their ability to inhabit anthropogenic sites, as well as the longevity of individuals. Hayes and Barry (10), based on Kolar and Lodge (4), found three variables that promote establishment success across taxon- omic groups: climate/habitat match, invasion success elsewhere and propagule pressure. Other authors came to the conclusion that propagule pressure is the only trait promoting invasion success across taxonomic groups (reviewed in 2,11).

In addition to such cross-taxonomic similarities in single variables or traits, species may also show similarities across taxa in sets of several traits relevant for invasion success. For this study, we test the following hypothesis: species of different taxonomic groups show similar combinations of invasion traits (i.e. traits that facilitate the invasion process). The alternative hypothesis, which we expect to be rejected, is that similar combinations of invasion traits are congruent with taxonomic groups. We assessed these hypotheses by compiling information on traits known to increase the probability that a species becomes invasive ("invasion traits"). The respective trait values were generalized in order to be applicable across various taxa and were compiled for 201 invasive species derived from seven major taxonomic groups. For each invasion trait, we compared the frequency of trait expressions among taxonomic groups, and to the results of published studies. According to our hypothesis, we expected no strong differences among taxonomic groups. Next, we applied cluster analysis to search for similarities among species with respect to invasion traits (for similar approaches focused on plants, see 9, 12). If taxonomic groups do not differ fundamentally concerning invasion traits, species of each taxonomic group should be dispersed across clusters.

\section{Method}

\section{Dataset}

Our dataset includes 201 invasive species (species established and spreading in an area beyond their native range). Aiming for a broad generalization of our findings, we chose species from a wide range of taxonomic groups, trophic levels, life forms, habitats, geographic origins and invaded ranges. For each species, we collected data on 13 invasion traits (Table 1 ) in the scientific literature, databases, and online sources (Supplementary material 1). Although unequal availability of these data precluded reaching a balanced number of species throughout all taxa, ecological traits, origins and target regions, we chose this approach to initiate novel (at least preliminary) insights from cross-taxonomic research, which we believe is essential for progressing in our understanding of species' invasiveness. 
Table 1. Description of invasion traits used to characterise each species. Traits have been chosen based on Heger (13). References indicating significance of the traits for invasion success are given in the rightmost column. Cases are indicated where the wording in the cited references differs from our formulation. In our dataset, trait values can be either "yes" or "no".

\begin{tabular}{|c|c|c|c|}
\hline & Invasion trait & Description & Reference \\
\hline \multirow{4}{*}{$\begin{array}{l}\frac{\hbar}{0} \\
\frac{0}{0} \\
\frac{1}{\pi} \\
\stackrel{0}{=}\end{array}$} & $\begin{array}{l}\text { Intentional } \\
\text { transport }\end{array}$ & $\begin{array}{l}\text { Is or was the transport of the species into the new } \\
\text { area predominantly intentional? }\end{array}$ & Hulme et al. (14) \\
\hline & $\begin{array}{l}\text { In IUCN Red } \\
\text { List }\end{array}$ & $\begin{array}{l}\text { Is the species classified as "near threatened" or } \\
\text { worse in the IUCN Red List of Threatened Species } \\
\text { (IUCN 2013)? }{ }^{+}\end{array}$ & $\begin{array}{l}\text { Lavoie et al. (15): narrow-ranging } \\
\text { species are less likely to be } \\
\text { dispersed via propagule } \\
\text { transportation vectors }\end{array}$ \\
\hline & $\begin{array}{l}\text { Transport as } \\
\text { diaspore }\end{array}$ & $\begin{array}{l}\text { Is the species often transported as diaspore or } \\
\text { another easily transportable life stage? }\end{array}$ & Foy et al. (16) \\
\hline & Seed bank & $\begin{array}{l}\text { Does the species form seed banks, or has it other } \\
\text { life stages able to survive a period of unfavourable } \\
\text { conditions? }\end{array}$ & $\begin{array}{l}\text { Martínez-Ghersa and Ghersa (17), } \\
\text { Figueroa et al. (18) }\end{array}$ \\
\hline \multirow{2}{*}{ 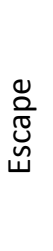 } & $\begin{array}{l}\text { Intentional } \\
\text { release }\end{array}$ & $\begin{array}{l}\text { Is the escape and naturalisation of the species in } \\
\text { most cases intentional? }\end{array}$ & Hulme et al. (14) \\
\hline & Release adult & $\begin{array}{l}\text { Are mainly organisms released that are in their } \\
\text { reproductive life stage? }\end{array}$ & $\begin{array}{l}\text { This trait has rarely been studied } \\
\text { but is likely to positively relate to } \\
\text { invasion success. }\end{array}$ \\
\hline \multirow{5}{*}{ 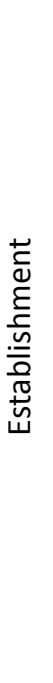 } & $\begin{array}{l}\text { Phenotypic } \\
\text { plasticity }\end{array}$ & $\begin{array}{l}\text { Does the species show pronounced morphological } \\
\text { or physiological plasticity? }\end{array}$ & Rejmánek (19) \\
\hline & $\begin{array}{l}\text { One individual } \\
\text { can form a } \\
\text { population }\end{array}$ & $\begin{array}{l}\text { May one individual suffice to build up a population, } \\
\text { e.g. because of vegetative reproduction, } \\
\text { parthenogenesis or else? }\end{array}$ & $\begin{array}{l}\text { Kolar and Lodge (4): vegetative } \\
\text { reproduction; Burns et al. (20): } \\
\text { autogamy; Statzner et al. (21): } \\
\text { ovoviviparity }\end{array}$ \\
\hline & $\begin{array}{l}\text { More than one } \\
\text { reproductive } \\
\text { phase per year }\end{array}$ & $\begin{array}{l}\text { Is there more than one clutch, phase of flowering, } \\
\text { spawning etc. per year? }\end{array}$ & $\begin{array}{l}\text { Kolar and Lodge (4): broods per } \\
\text { season }\end{array}$ \\
\hline & $\begin{array}{l}\text { Fecundity } \\
\text { above average }\end{array}$ & $\begin{array}{l}\text { Does the species produce more offspring than } \\
\text { ecologically similar, related species? }\end{array}$ & Rejmánek (19) \\
\hline & $\begin{array}{l}\text { Offspring in } \\
\text { first year }\end{array}$ & $\begin{array}{l}\text { Is an individual able to produce offspring in its first } \\
\text { year of life? }\end{array}$ & $\begin{array}{l}\text { Rejmánek (19): minimum } \\
\text { generation time }\end{array}$ \\
\hline \multirow{2}{*}{$\begin{array}{l}\frac{0}{\pi} \\
\frac{0}{2} \\
\text { nे }\end{array}$} & $\begin{array}{l}\text { Intentional } \\
\text { spread }\end{array}$ & $\begin{array}{l}\text { Is or was the spread of the species in the new area } \\
\text { predominantly intentional? }\end{array}$ & Kowarik (22) \\
\hline & $\begin{array}{l}\text { Spread as } \\
\text { active mobile } \\
\text { organism }\end{array}$ & $\begin{array}{l}\text { Does the species spread as an active mobile } \\
\text { organism? }\end{array}$ & Kolar and Lodge (4): migrating \\
\hline
\end{tabular}

\footnotetext{
${ }^{\dagger}$ We used the IUCN Red List (23) status as a proxy for rarity and thus for the probability of being transported accidentally (red-listed species are less likely to be accidentally transported than other species).
} 


\section{$\underline{\text { Invasion traits }}$}

The 13 traits included in the study were selected based on a checklist of factors influencing biological invasions (the INVASS model of invasion steps and stages, 13; see also 5). They cover the complete invasion process and have been shown to enhance invasion success (Table 1). We described them in a generalized, taxon-independent way, so that each trait is applicable to species of any taxonomic group (e.g. "one individual can form a population" instead of "vegetative reproduction").

The resulting data set consists of binary values ("yes" or "no" for each trait and each species). We chose this method of qualitative assessment because for most traits it is not possible to compare quantitative values in a meaningful way among taxonomic groups (e.g. the number of offspring). Nonetheless, three of the invasion traits have a strong association with taxonomic affiliation: "spread as active mobile organism" can never be found in plants, fungi, and red algae (39\% of all species in our data set), whereas "transportation as diaspore" and "seed bank" (in the broad sense of any organism's dormant life stages able to survive a period of unfavourable conditions) can never be found in vertebrates ( $71 \%$ of all animals, and $38 \%$ of all species in our dataset). This, of course, has implications for the interpretation of results and will be discussed below. In addition to species characteristics, we included information on human actions (e.g. deliberate transport), as they have a strong impact on invasion processes $(2,11,22)$.

\section{$\underline{\text { Taxonomic groups }}$}

We determined the taxonomic group of each species using the Tree of Life web project (24). The 201 analysed species belong to seven superordinate taxonomic groups (Supplementary material 1): 108 animals (Metazoa, 54\%), 70 green plants (all organisms commonly known as green algae and land plants, including mosses and ferns as well as seed plants, 35\%), six fungi (3\%), six heterokonts (brown algae, diatoms, and relatives; $3 \%)$, five bacteria (Eubacteria, 2\%), three red algae (Rhodophyta, 1\%) and three alveolates (dinoflagellates and relatives; $1 \%)$. The large percentage of animals and green plants in our dataset reflects the high proportion of these groups among studied invasive species (25). Despite the large size of these groups, we decided not to split animals and plants into smaller taxonomic units, as a further split would not have been possible in all other superordinate groups. Our criterion was to have larger taxonomic distances among than within taxonomic groups, and an unbalanced split of the groups would have obscured these distances. When interpreting our results we kept in mind that analysed numbers of species differ among taxonomic groups.

\section{Statistical analyses}

Descriptive statistics consisted of the assessment and comparison of the proportion of invasion traits of the taxonomic groups (incl. 95\% confidence intervals). In order to group the species in our dataset according to their invasion traits, we applied agglomerative hierarchical cluster analysis, using average linkage between groups as grouping criterion and simple matching for the similarity index (SPSS Statistics 22). The optimum number of clusters was determined based on the largest distance between the clusters in the distance matrix. We ignored the distance that separated all species with completely matching traits from the rest of the species. Clustering was rerun for the three best cluster solutions.

To assess if taxonomy reflects the statistical clusters, we produced a contingency table relating the two groupings (clusters and taxonomic groups) to each other. As a measure of contingency, we calculated Cramér's V (26). A Cramér's V of 1 shows a perfect fit of rows and columns in the contingency table; values larger than 0.3 are inter-preted as a relevant association and values larger than 0.6 as a strong relationship.

\section{Results}

Are frequencies of the investigated invasion traits similar across taxonomic groups?

To assess whether invasive species belonging to different taxonomic groups show similar frequencies in traits relevant for invasion success, we compared the relative frequencies of each invasion trait. In the following, we order the results of this analysis according to the invasion stage to which the respective traits are related.

Transport-For $59 \%$ of the species in our dataset, transportation to new regions is typically intentional (Fig.1; Supplementary material 2: Table S1). Especially green plants and animals are deliberately transported (77\% and $58 \%$ respectively) and these form the majority of species in the dataset. The species of the remaining five taxonomic groups in our dataset are 
predominantly $(67 \%$ of red algae and $83 \%$ of heterokonts) or exclusively (bacteria, fungi and alveolates) transported accidentally. Three per cent of the species in the dataset (only plants and animals) are included in the IUCN Red List, which means they have an especially low chance of getting transported accidentally. Thirty-six per cent of all species are transported as diaspores, and include species of green plants, fungi, alveolates, heterokonts and-to a small degree-animals (mainly aquatic species, e.g., Neogobius melanostomus and Dreissena polymerpha). Thirty-three per cent of the species in our dataset produce a seed bank or other dormant life stages; this trait is found in every taxonomic group (Fig.1; Supplementary material 2: Table S1). Fifty species ( $25 \%$ of all species included in our analysis, among them 37 plants, six animals, three heterokonts, two alveolates, one red algae and one fungus) share both traits, i.e. they are transported as diaspores and produce dormant life stages.

Escape-A relatively high proportion of the examined species (36\%) are released intentionally, again mainly plants and animals. All species with intentional release have also been intentionally transported. Sixtyfive per cent of all investigated species are in a reproductive stage when released. Concerning green plants, however, this is only true for about $31 \%$ of the species (among them mainly trees and aquatic species).
Establishment-Twenty-eight per cent of the analysed species are known to show pronounced morphological or physiological phenotypic plasticity; these are plants, red algae and animals. Fifty-two per cent of all species in the dataset are able to build up a population from a single individual (e.g. because females can reproduce asexually or store sperm cells, or due to layering). The only taxonomic group with less than $50 \%$ of species showing this ability is animals. Fifty-six per cent of the investigated species are able to reproduce more often than once a year. Only plants and animals include species lacking this ability. The number of offspring is higher than that of related taxa for $38 \%$ of the species, and more than $60 \%$ of the species in our dataset are able to produce offspring already in their first year of life. Green plants and animals are in our dataset the only groups that include species lacking this ability.

Spread-Dispersion within the exotic range was actively promoted by humans for only $9 \%$ of the species in our dataset (mainly plants used for landscaping, e.g. Spartina alterniflora and fish, e.g. Lates niloticus); $51 \%$ of the included species are able to spread actively.

To validate the recorded trait frequencies, we compared our results with other studies. Crosstaxonomic data compilations were available in the literature for three of our invasion traits. For

Table 2. Relative frequencies of invasion traits according to our dataset and compared to literature data. Frequencies (\%) are given for the invasion traits "intentional transport", "seed bank", and "intentional release"; dots mark empty fields.

\begin{tabular}{|c|c|c|c|c|c|c|c|c|}
\hline \multirow{2}{*}{ Invasion trait } & \multicolumn{2}{|c|}{ All taxa } & \multicolumn{2}{|c|}{ Plants } & \multicolumn{2}{|c|}{ Animals } & \multicolumn{2}{|c|}{ Fungi } \\
\hline & Our data & Literature & Our data & Literature & Our data & Literature & Our data & Literature \\
\hline \multirow{4}{*}{$\begin{array}{l}\text { Intentional } \\
\text { transport }\end{array}$} & 59 & $61^{14}$ & 77 & $69^{14}$ & 58 & $59^{14}$ & 0 & $0^{27}$ \\
\hline & $\bullet$ & $52^{27}$ & $\bullet$ & $89^{27}$ & $\bullet$ & $43^{27}$ & $\bullet$ & $\bullet$ \\
\hline & • & • & - & $68^{28}$ & • & $54^{11}$ & - & - \\
\hline & $\bullet$ & • & $\bullet$ & $>50^{29}$ & $\bullet$ & • & • & • \\
\hline Seed bank & 33 & $\bullet$ & 74 & $0.2^{30}$ & 6 & $0^{21}$ & 17 & • \\
\hline \multirow{2}{*}{$\begin{array}{l}\text { Intentional } \\
\text { release }\end{array}$} & 36 & $37^{14}$ & 31 & $12^{14}$ & 45 & $48^{14}$ & 0 & $\bullet$ \\
\hline & • & • & • & $1^{28}$ & • & • & $\bullet$ & • \\
\hline
\end{tabular}

${ }^{14}$ Hulme et al. (2008)

${ }^{27}$ Keller et al. (2009): nonindigenous freshwater species in Great Britain

${ }^{28}$ Lambdon et al. (2008): naturalised alien plant species in Europe

${ }^{29}$ Mack and Erneberg (2002): naturalised plant species in the United States

${ }^{11}$ Lockwood et al. (2007): re-analysis of data given on p. 33

${ }^{30}$ Bennett (2001): invasive plant species in the Great Lakes National Parks

${ }^{21}$ Statzner et al. (2008): invertebrates in Europe 

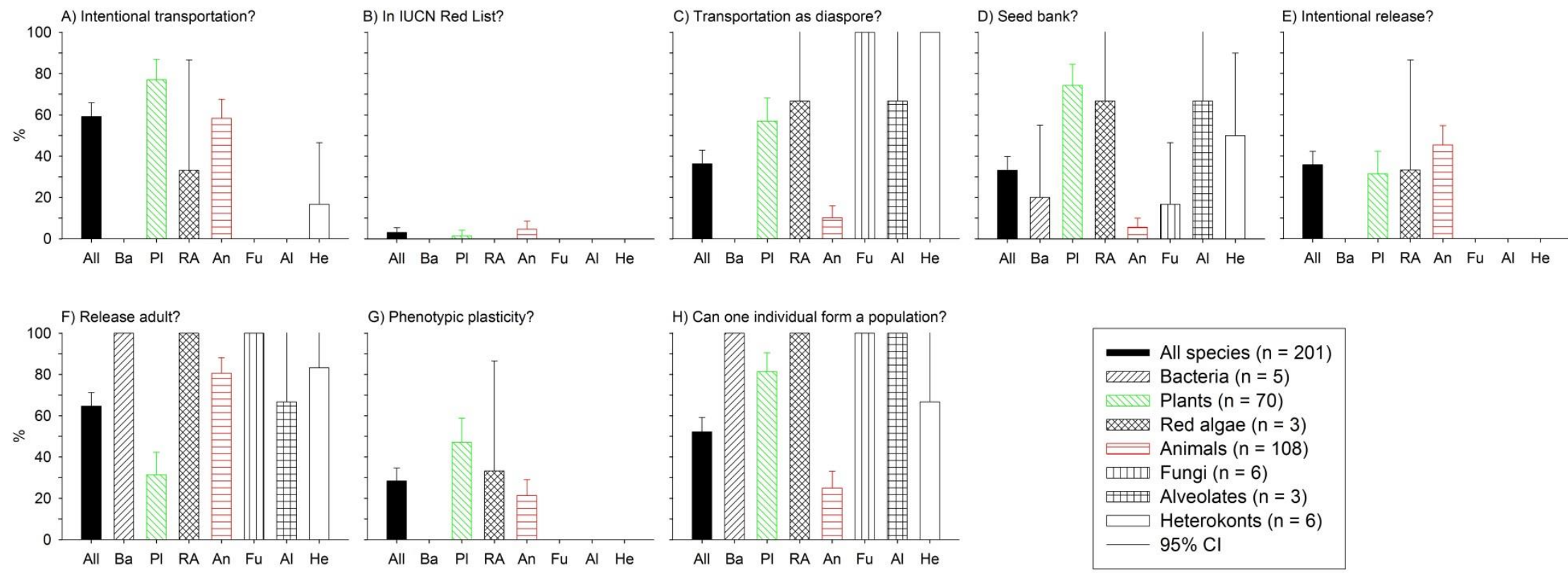

All Ba PI RA An Fu Al $\mathrm{He}$

All Ba PI RA An Fu Al He
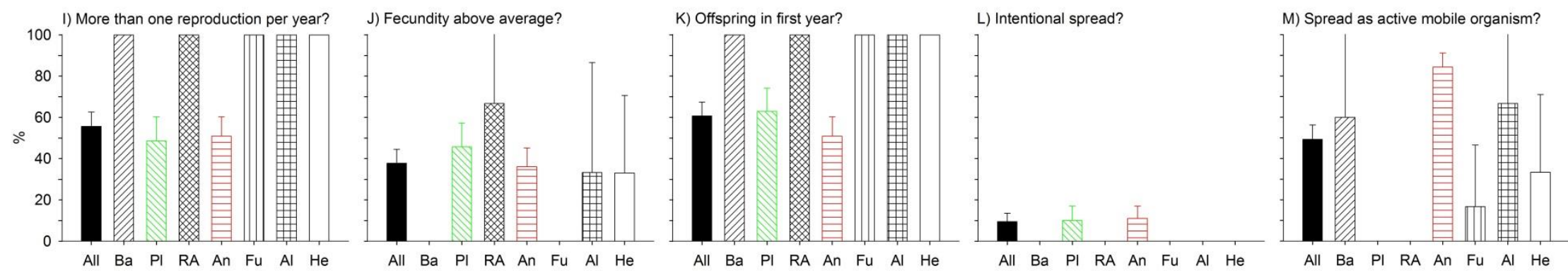

Figure 1. Relative frequencies of invasion traits. Frequencies $(+95 \% \mathrm{Cl})$ are given for all species in our dataset and for each of the seven taxonomic groups separately. Exact values are provided in Supplementary material 2: Table S1. 
"intentional transport" and "intentional release", these studies reported similar frequencies as in our dataset (Table 2). In regards to "seed bank", the frequencies reported in Bennett (30) and Statzner et al. (21) suggest that our approach might have overestimated the number of species able to build up a seed bank. An alternative explanation would be that our study differs from Bennett (30) and Statzner et al. (21) in how "seed bank" is defined.

Comparing our recorded frequencies among taxonomic groups, significant differences in trait frequencies can be found (e.g. for "transport as diaspore", "release adult"; cf. 95\% Cls in Fig. 1). For other invasion traits, though, differences are less pronounced ("in IUCN Red List", "intentional release", "offspring in the first year", "intentional spread"). The two taxonomic groups with the largest sample sizes, plants and animals, differ significantly in the frequencies of several invasion traits (e.g. "phenotypic plasticity", "can one individual form a population"). Other invasion traits, however, are similarly frequent in all seven taxonomic groups (e.g. "intentional release", "more than one reproductive phase per year", "intentional spread").

Taxonomic composition of clusters: Are clusters classifying the species according to invasion traits congruent with taxonomic groups?

Cluster analysis, using all 13 invasion traits and all 201 species, indicates that assigning species to two, three or five clusters are the three best clustering solutions. All three cluster solutions are based on the same branching pattern. Fig. 2 shows the main furcations of the underlying dendrogram, with cluster solutions differing in the number of furcations included: Only one furcation is needed to reach the 2cluster solution; for the 3-cluster solution, Cluster 1 of the two clusters identified in the 2-cluster solution is further split into two; and for the 5-cluster solution, Clusters 1 and 2 of the 3-cluster solution are each split into two (Fig. 2).

In the 5-cluster solution, Cluster $1(n=46)$ includes species from all seven taxonomic groups (Fig. 2): all red algae and alveolates can be found here, plus $40 \%$ of all bacteria, $83 \%$ of all fungi and $67 \%$ of all heterokonts (Supplementary material 2: Table S2). Twenty-six per cent of all green plants and $10 \%$ of all animals are included as well. The 41 species contained in Cluster 2 are animals, bacteria, fungi and heterokonts. Thirty-two per cent of all animals are classified into this cluster, additionally three of the five bacteria, one of the six fungi and one of the six heterokonts. Cluster $3(n=39)$ is dominated by green plants: it contains $51 \%$ of all plant species in our data set. Additionally, two animal species (Daphnia lumholtzi and Rapana venosa) and a heterokont (Undaria pinnatifida) can be found in this cluster. The 64 species of Cluster 4 are mainly animals (59 animal species, representing $55 \%$ of all animal species included in this study), complemented by five plant species (Cupressus macrocarpa, Pinus nigra, $P$. strobus, Pseudotsuga menziesii and Lysichiton americanus). Cluster 5 is the smallest group $(n=11)$ and contains only green plants.

The analysis of the respective contingency table (Supplementary material 2: Table S2) revealed that there is a weak association between the five clusters and the taxonomic groups (Cramér's $\mathrm{V}=0.478, p<$ 0.001 ; Table 3 ). The association between the three clusters in the 3-cluster solution and the taxonomic groups is stronger (Table 3). Here, one cluster contains a mixture of all taxonomic groups, a second cluster is dominated by animals and a third contains only plants (Fig. 2; Supplementary material 2: Table S3). The two clusters in the 2-cluster solution show the strongest association with the taxonomic groups (Table 3). Sixty-eight per cent of the 96 species in cluster 1 are plants and $90 \%$ of the 105 species in cluster 2 are animals (Fig. 2; Supplementary material 2: Table S4).

\section{Discussion}

Species from different taxonomic groups show similar combinations of invasion traits

We hypothesized that species of different taxonomic groups show similar combinations of invasion traits. This would be confirmed if clusters of

Table 3. Association of the three best cluster solutions with taxonomic groups and potential invader types. Strength of association is given as Cramér's V. Higher values indicate stronger association; a Cramér's $V$ of 1 would indicate a perfect fit of rows and columns in the respective contingency table and thus congruence of the two classifications.

\begin{tabular}{lccc}
\hline & $\begin{array}{c}\text { 5- cluster } \\
\text { solution }\end{array}$ & $\begin{array}{c}\text { 3-cluster } \\
\text { solution }\end{array}$ & $\begin{array}{c}\text { 2-cluster } \\
\text { solution }\end{array}$ \\
\hline Taxa & $\begin{array}{c}0.478 \\
(p<0.0001)\end{array}$ & $\begin{array}{c}0.576 \\
(p<0.0001)\end{array}$ & $\begin{array}{c}0.789 \\
(p<0.0001)\end{array}$ \\
$\begin{array}{l}\text { Potential } \\
\text { invader } \\
\text { types }\end{array}$ & 0.584 & 0.598 & 0.743 \\
\hline
\end{tabular}




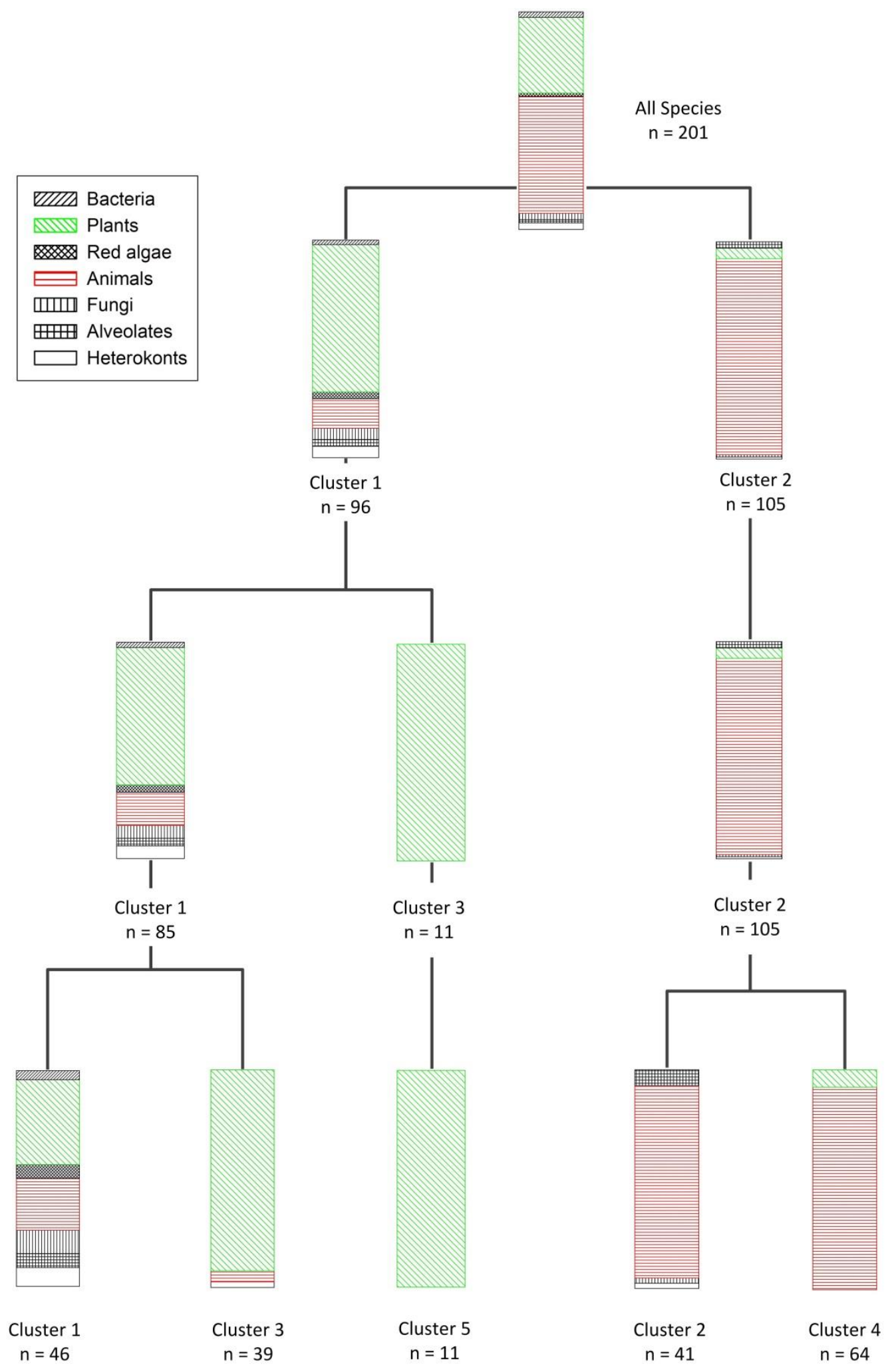

Figure 2. Results of cluster analyses depicted as a schematic dendrogram. 201 invasive species have been clustered according to similarity in invasion traits. For the three best cluster solutions, size and taxonomic composition of statistical clusters are shown: 2-cluster solution in the second row, 3-cluster solution in the third row, and 5-cluster solution in the fourth row. Exact values are provided in Supplementary material 2: Tables S2-4. 
species with similar invasion traits contain species of different taxonomic groups. All in all, our results support this notion. In the 5-cluster solution, Cluster 1 contains species from all seven taxa, and the three clusters with species of three or more taxonomic groups (Clusters 1, 2 and 3) contain $60 \%$ of all species. All taxonomic groups with a sample size of more than three species in our dataset can be found in more than one cluster. The two largest groups (green plants and animals) are both dispersed across four out of five clusters. These results suggest that species in fact show similar combinations of invasion traits across taxonomic groups. Interestingly, the composition of clusters is also heterogeneous on a smaller taxonomic scale: the 36 animals in Cluster 2, for example, include one starfish, 3 molluscs, 15 arthropods and 17 vertebrates (one lamprey, three fish, 3 amphibians, 3 reptiles, 4 birds and 3 mammals). The 36 green plants in Cluster 3 are comprised of one moss, three ferns, two conifers and 30 angiosperms. Angiosperms are scattered over 4 out of the 5 clusters. Nevertheless, three clusters (2, 3 and 4) are strongly dominated by one taxonomic group, and one cluster (Cluster 5 with 11 species in total) contains exclusively species from one taxonomic group (green plants). In the 3-cluster solution, two clusters are dominated by one taxonomic group, whereas one cluster contains a mix of all seven taxa. In the 2-cluster solution, one cluster is dominated by plants and the other by animals, but still, all taxa represented by more than three species in our dataset are present in both clusters.

Figure 1 shows that some invasion traits can be found frequently across different taxa, but a connection between taxonomic affiliation and differences in invasion mechanisms cannot be neglected. For example, ecological differences between animals and plants are mirrored by significant differences in invasion-trait frequencies. On the one hand, thus, there seem to be differences among taxonomic groups in what drives biological invasions, while on the other hand, cluster analysis indicates the existence of important taxonindependent drivers of invasions. Our results call for more cross-taxonomic analyses of invasion traits to disentangle these two categories of drivers. Research on invasion traits has often focused on traits that are only relevant for the focal taxonomic group, e.g. seed weight for plants (31) or brain mass for animals (32). It would be desirable for future data compilations to also integrate data on traits relevant for multiple taxonomic groups.
Statistical clusters are not congruent with taxonomic groups: Do trait combinations reflect certain invader types?

Hierarchical cluster analysis grouped together species with similar combinations of invasion traits, and our analyses show that the resulting clusters are similar to, but not congruent with taxonomic groups. Each cluster is characterized by a complex combination of invasion traits (Supplementary material 1). In the following, our approach to the interpretation of the clusters is to specify post-hoc hypothetical invader types characterised by a defined combination of traits, and to analyse how good these hypothetical invader types match the clusters.

It has previously been shown for a number of taxonomic groups that during different steps of the invasion process, different species characteristics can be useful $(4,32-35$, but see 36$)$. It is also well known that the promoting influence of humans on species invasions has to be considered (e.g., 37). Thus, species having traits helpful during every single step of the invasion process, and which in addition may even be promoted by humans, are supposedly very successful invasive species. Nevertheless, invasion success can also be achieved with only a subset of these helpful traits: for instance, if due to the contingencies inherent to invasion processes particular traits are not necessary to advance in the invasion process, a species can be successful without these traits (5). We suggest that invasion processes differ with regards to which of the invasion steps (transport, escape, establishment and spread) is the most challenging one from the viewpoint of the species, also depending on the introduction pathway and the ecosystem where it is introduced. Accordingly, we suggest that invasive species can be classified into invader types, each having traits especially suitable to overcome one of the invasion steps.

In a preliminary attempt to further explore this idea, we conceived five hypothetical invader types post hoc (Table 4), four of them characterized by a combination of traits that help species to advance during specific invasion stages (transport, escape, establishment and spread), and one characterized by human promotion. Species in our dataset were assigned to one of the invader types when they matched the relevant trait combinations more than $50 \%$. This method was applied to 142 species, although 59 species could not be assigned to a specific invader type because they either did not match any of the types (18 species) or qualified 
Table 4. Characterisation of five hypothetical invader types, using contrasting combinations of invasion traits. Invader types 1-4 include traits that help species to advance during the four stages of the invasion process; invader type 5 includes traits that indicate promotion by humans. For a more detailed description of the invasion traits, see Table 1 . Dots mark empty fields.

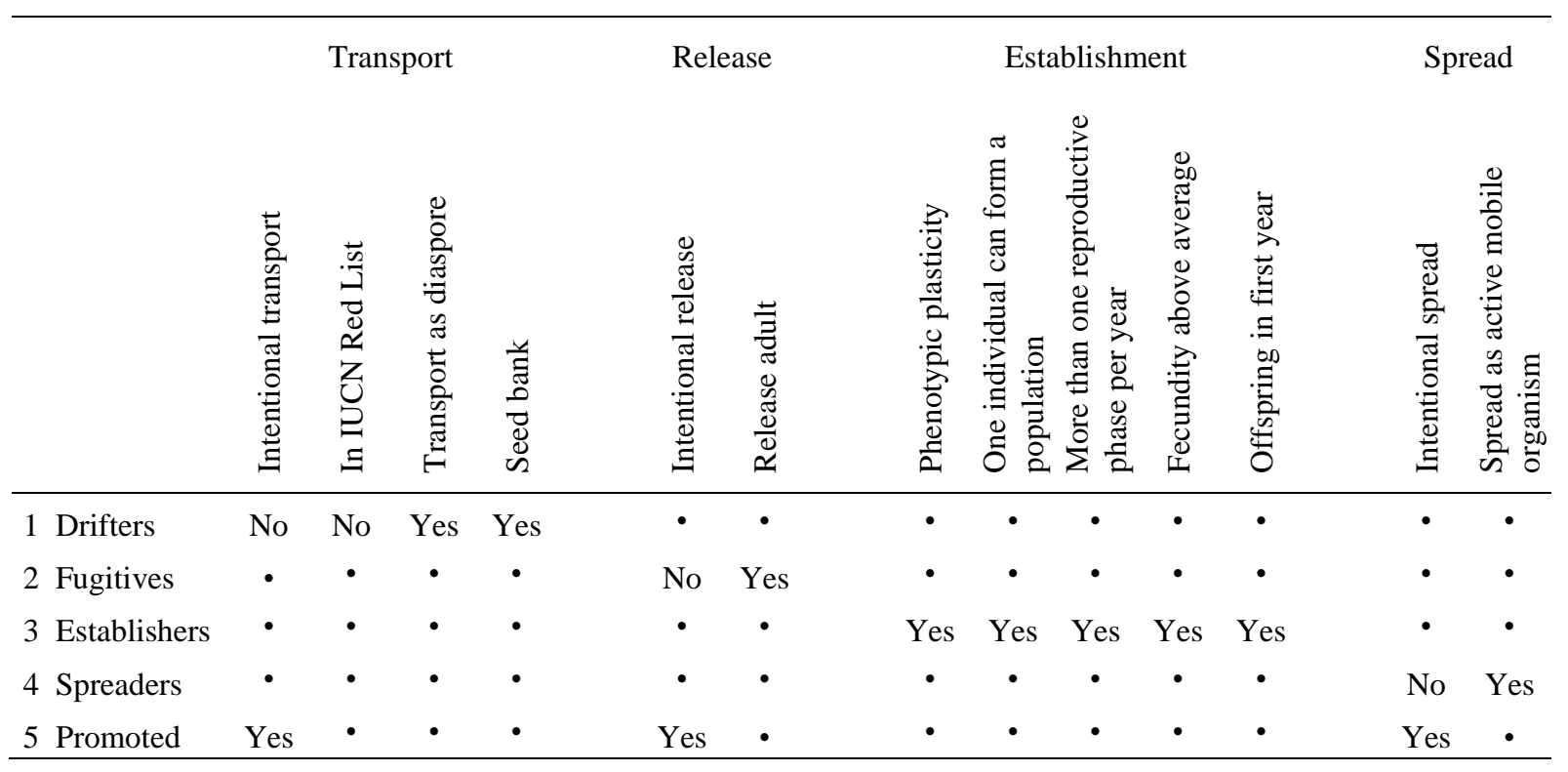

equally for multiple types (41 species). Twenty-five species were assigned to the invader type "drifters", 23 to the type "fugitives", 30 to "establishers", 40 to "spreaders" and 24 to the invader type "promoted". Figure 3 shows the frequencies of the hypothetical invader types for each cluster. Except for the "establishers", each invader type has its main occurrence ( $\geq$ $60 \%$ ) in just one cluster (Supplementary material 2: Table S5). Calculating the match between statistical clusters and the preliminary hypothetical invader types using Cramér's V, we observed a better match between clusters and invader types than between clusters and taxonomic groups for the 5- and the 3cluster solution (Table 3). Note that this comparison is conservative, as the category "no assignment" was included as one of the hypothetical invader types. The significant association of the clusters with the hypothetical invader types indicates that the latter reflect some of those similarities of invasion traits among species that lead to their clustering. The trait combinations we found to cluster together are not exactly those trait combinations we suggested to be especially useful during specific invasion stages, or the promotion of the species through human actions (i.e. Cramér's V for the comparison of clusters and hypothetical invader types is not 1). But as indicated by the high values of Cramér's $V$, the hypothetical invader types explain the clusters at least as good as the taxonomic groups do. This indicates that distantly related invasive species do not only share invasion traits, but that moreover, these shared invasion traits are linked to specific properties of the invasion process.

\section{Conclusion}

Our analysis of 13 "invasion traits" in 201 invasive species indicates that the same mechanisms might drive biological invasions across taxa. However, this study only represents a first step as (i) our dataset comprises only a small (and taxonomically unbalanced) subset of invasive species, (ii) we did not include a comparison with non-invasive species, and (iii) we assessed the "invasion traits" qualitatively rather than quantitatively. Nevertheless, this study delivers some important insights. Our results suggest the existence of recurring combinations of invasion traits (invader types), which reflect different possibilities to become a successful invader. A promising line of future research could be to identify syndromes of invasion situations that can be overcome by such specific combinations of invasion traits, independently of taxonomic affiliation. Such research focusing on combinations of invasion traits appears to have more potential than continuing the rather fruitless search for single invasion traits to explain the invasion success of all invaders. 


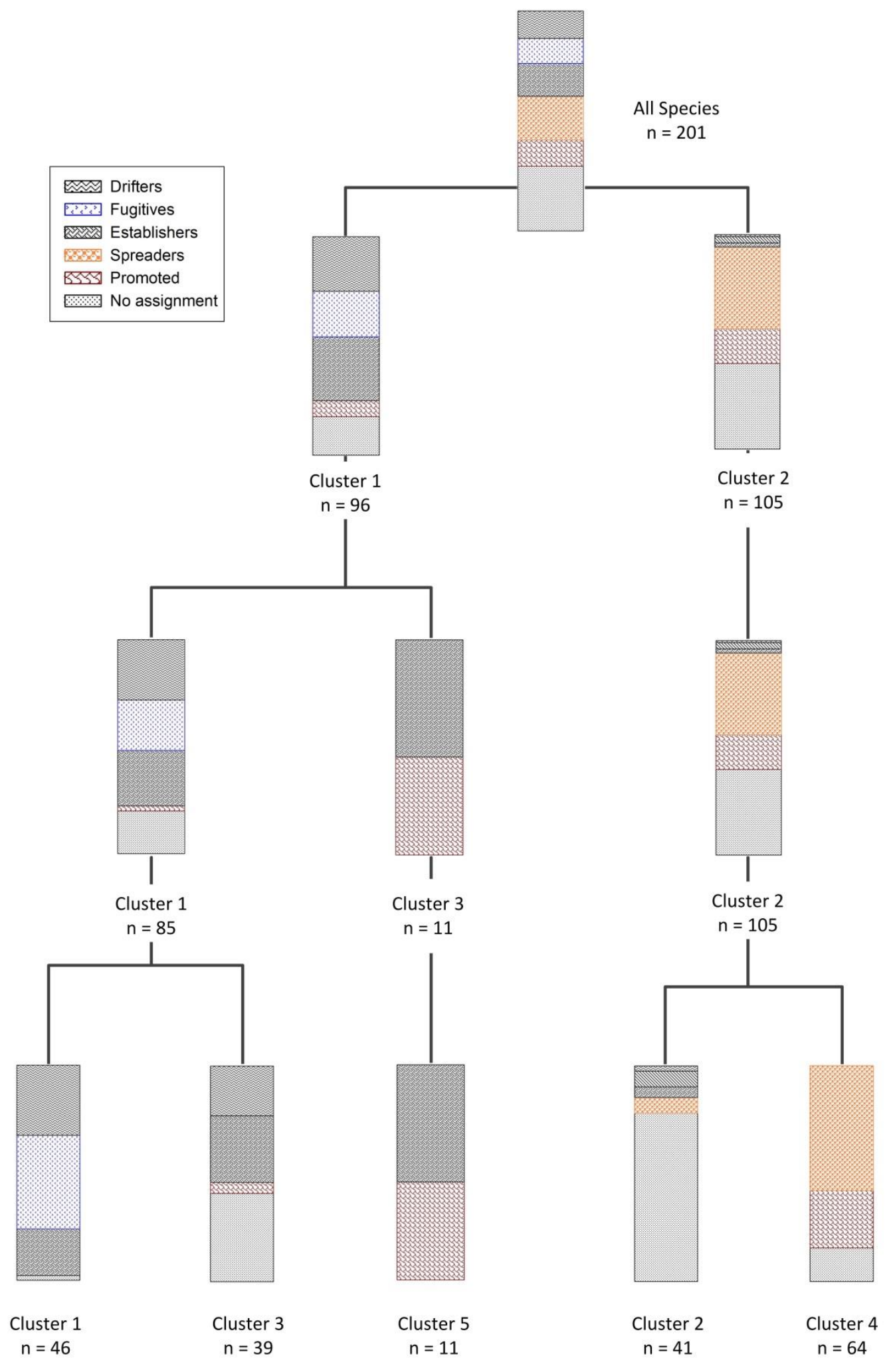

Figure 3. Contributions of hypothetical invader types to clusters. For each cluster given in Fig. 2 the per cent frequencies of species corresponding to one of five hypothetical invader types is shown: 2-cluster solution in the second row, 3-cluster solution in the third row, and 5-cluster solution in the fourth row. Exact values are provided in Supplementary material 2: Tables S5-7. 


\section{Acknowledgments}

We thank Johannes Kollmann for helpful comments on the manuscript, and Morgan McCarthy for language corrections. JMJ was financially supported by the Deutsche Forschungsgemeinschaft (JE 288/2-1, JE 288/4-1, JE 288/9-1).

\section{References}

1. Jeschke JM, Gómez Aparicio L, Haider S, Heger T, Lortie CJ, Pyšek P, Strayer DL (2012) Taxonomic bias and lack of cross-taxonomic studies in invasion biology. Frontiers in Ecology and the Environment 10:349-350. CrossRef

2. Blackburn TM, Lockwood JL, Cassey P (2009) Avian Invasions. Oxford University Press (Oxford):1-303.

3. Williamson M (1996) Biological Invasions. Chapman \& Hall (London). CrossRef

4. Kolar CS, Lodge DM (2001) Progress in invasion biology: predicting invaders. Trends in Ecology and Evolution 16:199-204. CrossRef

5. Heger T, Trepl L (2003) Predicting biological invasions. Biological Invasions 5:313-321. CrossRef

6. Theoharides KA, Dukes JS (2007) Plant invasion across space and time: factors affecting nonindigenous species success during four stages of invasion. New Phytologist 176:256-273. CrossRef

7. Blackburn TM, Pyšek $P$, Bacher $S$, Carlton JT, Duncan RP, Jarošík V, Wilson JRU, Richardson DM (2011) A proposed unified framework for biological invasions. Trends in Ecology and Evolution 26: 333-339. CrossRef

8. Pyšek $P$, Bacher $S$, Chytry $M$, Jarosik V, Wild J, Celesti-Grapow L, Gasso N, Kenis M, Lambdon PW, Nentwig W, Pergl J, Roques A, Sadlo J, Solarz W, Vila M, Hulme PE (2010) Contrasting patterns in the invasions of European terrestrial and freshwater habitats by alien plants, insects and vertebrates. Global Ecology and Biogeography 19:317-331. CrossRef

9. Newsome AE, Noble IR (1986) Ecological and physiological characters of invading species. In Groves RH, Burdon JJ (Eds) Ecology of biological invasions. Cambridge University Press (Cambridge):1-20.

10. Hayes KR, Barry SC (2008) Are there any consistent predictors of invasion success? Biological Invasions 10:483-506. CrossRef

11. Lockwood JL, Hoopes MF, Marchetti MP (2007) Invasion Ecology. Blackwell (Malden): 1-304.
12. Thuiller W, Richardson DM, Rouget $M$, Proches $S$, Wilson JRU (2006) Interactions between environment, species traits, and human uses describe patterns of plant invasions. Ecology 87:1755-1769. CrossRef

13. Heger T (2004) Zur Vorhersagbarkeit biologischer Invasionen. Entwicklung und Anwendung eines Modells zur Analyse der Invasion gebietsfremder Pflanzen. Neobiota 4, Technische Universität Berlin (Berlin): 1-197.

14. Hulme PE, Bacher $S$, Kenis $M$, Klotz $S$, Kuhn I, Minchin D, Nentwig W, Olenin S, Panov V, Pergl J, Pyšek P, Roques A, Sol D, Solarz W, Vila M (2008) Grasping at the routes of biological invasions: a framework for integrating pathways into policy. Journal of Applied Ecology 45:403-414. CrossRef

15. Lavoie $C$, Shah MA, Bergeron A, Villeneuve $P$ (2013) Explaining invasiveness from extent of native range: new insights from plant atlases and herbarium specimens. Diversity and Distributions 19:98-105. CrossRef

16. Foy CL, Forney DR, Cooley WE (1983) History of weed introductions. In Wilson CL, Graham CK (Eds) Exotic plant pests and North American agriculture. Academic Press (New York): 65-92. CrossRef

17. Martínez-Ghersa MA, Ghersa CM (2006) The relationship of propagule pressure to invasion potential in plants. Euphytica 148:87-96. CrossRef

18. Figueroa JA, Castro SA, Marquet PA, Jaksic FM (2004) Exotic plant invasions to the mediterranean region of Chile: causes, history and impacts. Revista Chilena De Historia Natural 77:465-483. CrossRef

19. Rejmánek M (2011) Invasiveness. In Simberloff D, Rejmánek M (Eds) Encyclopedia of biological invasions. University of California Press (Berkeley): 379-385.

20. Burns JH, Ashman TL, Steets JA, Harmon-Threatt A, Knight TM (2011) A phylogenetically controlled analysis of the roles of reproductive traits in plant invasions. Oecologia 166:1009-1017. CrossRef

21. Statzner B, Bonanda N, Doledec S (2008) Biological attributes discriminating invasive from native European stream macroinvertebrates. Biological Invasions 10:517-530. CrossRef

22. Kowarik I (2003). Human agency in biological invasions: secondary releases foster naturalisation and population expansion of alien plant species. Biological Invasions 5:293-312. CrossRef

23. IUCN (2013) IUCN Red List of Threatened Species. Version 2010.4. http://www.iucnredlist.org. Accessed October 2013. 
24. Maddison DR, Schulz K-S (2010) The Tree of Life Web Project. http://tolweb.org/tree/. Accessed October 2010.

25. Pyšek $P$, Richardson DM, Pergl J, Jarosik V, Sixtova Z, Weber E (2008) Geographical and taxonomic biases in invasion ecology. Trends in Ecology and Evolution 23:237-244. CrossRef

26. Conover WJ (1999) Practical nonparametric statistics, 3rd edn. Wiley (New York).

27. Keller RP, Ermgassen P, Aldridge DC (2009) Vectors and timing of freshwater invasions in Great Britain. Conservation Biology 23:1526-1534. CrossRef

28. Lambdon PW, Pysek P, Basnou C, Hejda M, Arianoutsou M, Essl F, Jarosik V, Pergl J, Winter M, Anastasiu P, Andriopoulos P, Bazos I, Brundu G, Celesti-Grapow L, Chassot $P$, Delipetrou $P$, Josefsson M, Kark S, Klotz S, Kokkoris Y, Kuhn I, Marchante H, Perglova I, Pino J, Vila M, Zikos A, Roy D, Hulme PE (2008) Alien flora of Europe: species diversity, temporal trends, geographical patterns and research needs. Preslia 80:101-149.

29. Mack RN, Erneberg M (2002) The United States naturalized floras: largely the product of deliberate introductions. Annuals of the Missouri Botanical Garden 89:176-189. CrossRef

30. Bennett JP (2001) Type characters of non-native plant species in Great Lakes National Parks (USA). In Brundu G, Brock JH, Camarda I, Child LE, Wade PM (Eds) Plant Invasions. Species Ecology and Ecosystem Management. Backhuys (Leiden): 199206.

31. Pyšek $P$, Krivanek $M$, Jarosik V (2009) Planting intensity, residence time, and species traits determine invasion success of alien woody species. Ecology 90:2734-2744. CrossRef

32. Jeschke JM, Strayer DL (2006) Determinants of vertebrate invasion success in Europe and North America. Global Change Biology 12:1608-1619. CrossRef

33. Cassey P, Blackburn TM, Russell GJ, Jones KE, Lockwood JL (2004) Influences on the transport and establishment of exotic bird species: an analysis of the parrots (Psittaciformes) of the world. Global Change Biology 10:417-426. CrossRef

34. Dehnen-Schmutz K, Touza J, Perrings C, Williamson M (2007) The horticultural trade and ornamental plant invasions in Britain. Conservation Biology 21:224-231. CrossRef

35. Dawson W, Burslem D, Hulme PE (2009) Factors explaining alien plant invasion success in a tropical ecosystem differ at each stage of invasion. Journal of Ecology 97:657-665. CrossRef

36. Ribeiro F, Elvira B, Collares-Pereira MJ, Moyle PB (2008) Life-history traits of non-native fishes in Iberian watersheds across several invasion stages: a first approach. Biological Invasions 10:89-102. CrossRef

37. Hulme PE (2009) Trade, transport and trouble: managing invasive species pathways in an era of globalization. Journal of Applied Ecology 46:1018. CrossRef 